\title{
GENERATIVE DESIGN OF STRUCTURAL STEEL JOINTS
}

Scientific paper

(Received: 21 May 2021; accepted: 6 October 2021)

\author{
Anton Kralj \\ University of Zagreb, Faculty of Civil Engineering, Research Assistant \\ Davor Skejić \\ University of Zagreb, Faculty of Civil Engineering, Full Professor \\ Corresponding author: davor.skejic@grad.unizg.hr
}

\begin{abstract}
Structural project is based on technical regulations, structural codes, construction conditions, and client requirements. Through the structural design process, some important decisions that can significantly affect the final result must be implemented. The most important factor for optimal design is the reduction in material and overall work costs. Selecting appropriate joint configurations that can reduce the overall weight and work on the structure is critical. To examine a significant number of possible configurations and their effect on structural behavior, the generative design method (GDM) is used. In this study, software is custom developed, and a relevant example of generative joint structural design is provided. The methodology for the optimal joint and structure design is described comprehensively. The final results show that the GDM is an effective methodology for application in the design of steel structures.
\end{abstract}

Keywords: Generative design; EN 1993-1-8; automation; optimization; steel; beam-to-column joint. 


\section{INTRODUCTION}

The design of a steel structure is a complex process involving interactive procedures, whose main goal, in addition to reliability, is the economic justification of the construction. This implies a reduction in material consumption $\left(\mathrm{CO}_{2}\right.$ footprint) and the overall construction work. One of the factors that significantly affect the design of structural steel is joints. By selecting the appropriate joint, the performance of the entire structure can be improved, which can consequently result in a more optimal bending moment distribution across members, less weight of the entire structure, and minimum stiffening of joints, thereby reducing the amount of welding required. Engineering assessment is a key step in achieving these of goals. Therefore, any decision-making assistance will reduce the time required in the design phase and reduce the possibility of implementing less optimal decisions.

The main aim of this study is to define a methodology that can be applied for the fast and economical design of structural steel joints and steel frame structures. This method, termed the generative design method (GDM), is a method for evaluating a significant number of configurations in a short period of time with defined constraints, thereby enabling designers to realize decisions rapidly and rationally. Every joint configuration is calculated based on EN 1993-1-8 [1], which specifies a method for the design of steel joints and constitutes the GDM evaluation process. This process is controlled using an algorithm developed in C \# (C-sharp), and rules are specified for creating common joint configurations with components such as end-plates, bolts, haunch, and stiffeners. Furthermore, the GDM provides an adequate visual presentation of results obtained via a diagram that displays hyperdimensional data, which is known as the parallel coordinate plot (PCP).

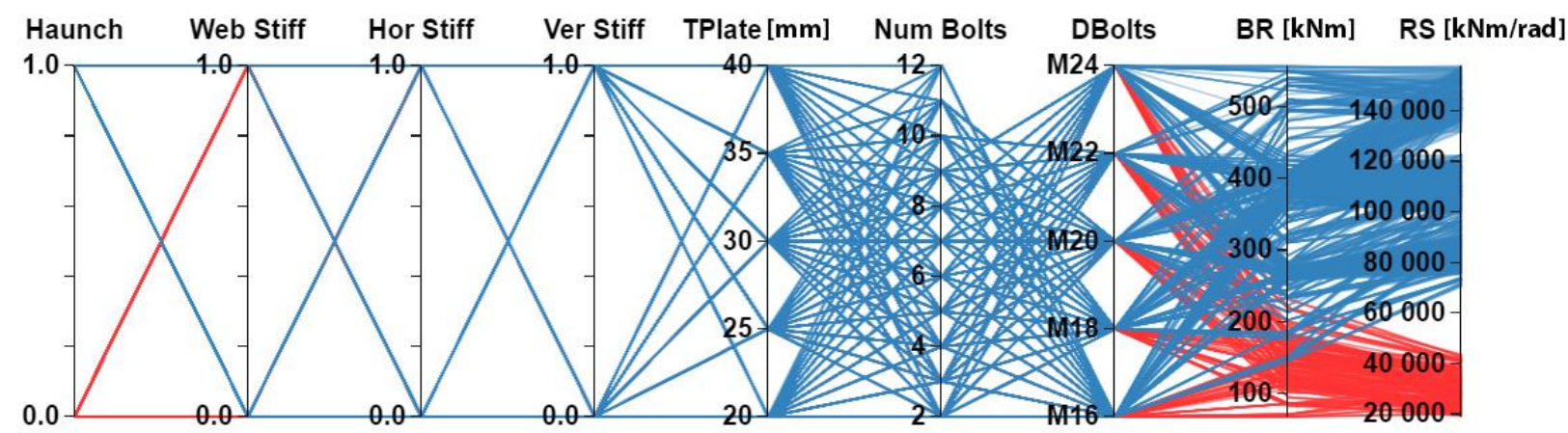

Figure 1 Parallel coordinate plot (PCP) for different joint configurations

Figure 1 shows the PCP of different joint configurations. The vertical axes represent the names and values of the input (static), variable, and output parameters described in Section 4. The blue and red lines represent different joint configurations.

It is noteworthy that the application of the GDM contributes positively to other industries as well. The potential of implementing this method in daily practice, in addition to economic factors, includes time gains in the design process. The design of more economical buildings and, consequently, reduction in $\mathrm{CO}_{2}$ emission is a trend that affects the entire construction industry; in this regard, GDM is an indispensable method.

\section{GENERATIVE DESIGN METHOD}

Humans have been imitating nature and laws since time immemorial, e.g., to create different types of products in the design process [2]. The GDM has become increasingly popular in recent years, primarily because of the increased capability of computers. It mimics nature using algorithms inspired by, for example, bone growth in animals [3]. The GDM was first used primarily to encourage creativity and divergent thinking in humans. The main goal of this method is to develop and propose a set of credible configurations for a defined problem that satisfies a set of constraints. Currently, it is used in mechanical design, architecture, construction, microstructural design, smart structures, micromechanics, and other industries. Moreover, the rapid advancements in additive manufacturing render generative design practical for application in structural engineering [4].

Kralj, A, Skejić, D 
Generative design is a process of defining high-level goals and constraints, and then performing computation to automatically investigate a range of configurations that satisfy the desired requirements [5]. The GDM can be understood the most easily based on its process. Input (static) data are members or parameters that have default values and are strictly defined by the user. These parameters are used to define and limit the output data. Subsequently, rules and algorithms are defined, by which the formation of parameters in potential configurations begins. The parameters inside algorithms interact with each other within the virtual environment driven by a unique set of rules and algorithms that constitute a complete intelligent system [5]. This part of the process is enabled by advances in computer technology, microprocessors, and cloud computing power. The configurations exist in the form of a digital display, and they can be evaluated and graded based on the obtained output data (results). Generative design is built upon itself based on the following rules and algorithms as its limitations [5]. The algorithm offers a significant number of different configurations based on the change in input parameters and constraints, allowing the user to possess maximal control of the output data [6]. This allows the user to investigate the configurations and then change the constraints based on their requirements. Hence, the user can investigate a significant number of configurations via computing capabilities and identify the appropriate requirements. This is only achievable by analyzing the obtained data simultaneously using the PCP (see example in Figure 1). The PCP represents n-dimensional data points in a coordinate system, interpreted by a polyline (curve) that intersects parallel axes at specific points. This is a viable tool for hyperdimensional data visualization [7]. Each curve represents a combination of input parameters and outputs, allowing the user to easily detect a particular combination in complex data structures. The program interface and a portion of the algorithm code that is developed specifically for the purpose of this study, where the structural engineer can change the input parameters of the GDM, are shown in Figure 2.

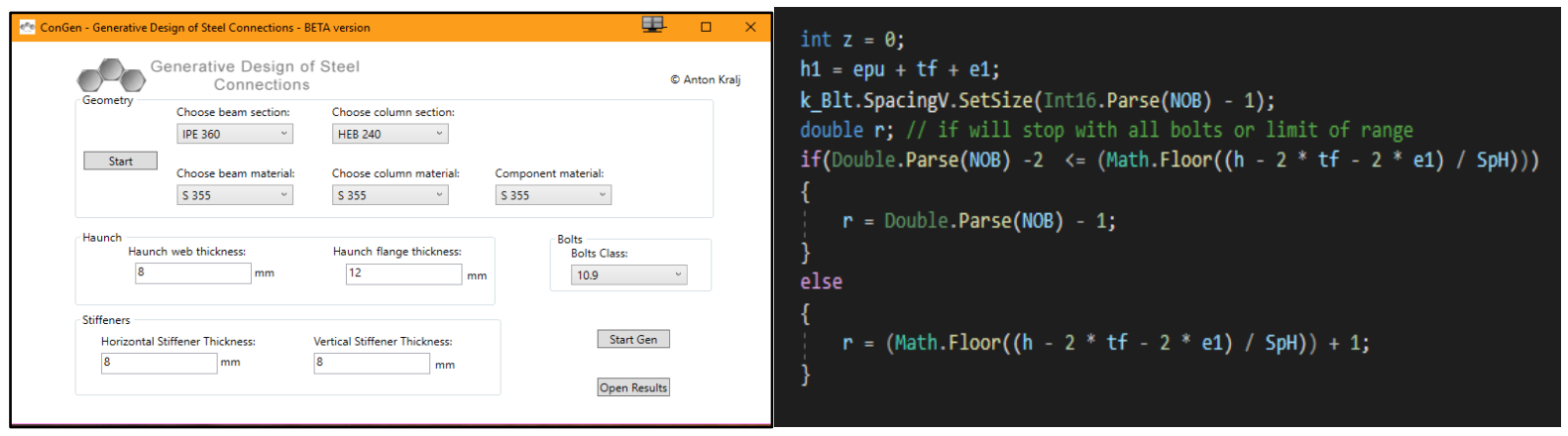

Figure 2 Example of GDM program interface (left) and a portion of its code algorithm (right)

\section{DESIGN OF STEEL JOINTS BASED ON EUROCODE}

By performing the structural analysis and design of the steel frame, we attempted to identify the optimal configuration of the main structural members [8]. In this regard, it is important to consider the interaction between the members, which is dependent on the joint stiffness [9]. Hence, structural analysis becomes an interactive procedure between selecting members and the adequate joint rotational stiffness that can be obtained using the appropriate joint configuration. Selecting the appropriate joint configuration implies identifying an optimal joint configuration that satisfies the analysis assumptions and requirements obtained from the analysis of the structure [10], [11].

EN 1993-1-8 [1] specifies rules for defining and calculating the main joint structural properties required for analysis and design. In addition, to ensure the joint rotational capacity, the two most important joint properties to be considered are the rotational stiffness and bending resistance. These two properties directly affect each other; more precisely, the joint rigidity (stiffness) affects the joint flexural resistance, and vice versa.

Joint rotational stiffness affects the behavior of an entire structure, such as its displacement and stability. The joint rotational stiffness was calculated using a component method defined in EN 1993-1-8 [1]. The rotational stiffness can be classified into three categories: rigid, semi-rigid, and pinned (Figure 3). This classification is obtained by comparing the joint stiffness with the limit values, which depend on the structural system. Pinned joints

Kralj, A, Skejić, D 
should be able to transmit internal forces without developing significant moments that may adversely affect the members or the entire structure. Joints classified as rigid may be assumed to possess sufficient rotational stiffness to justify the analysis based on complete and continuous framing. Semi-rigid joints (Zone 2) appear between these limits (boundary lines), as shown in Figure 3 [1].

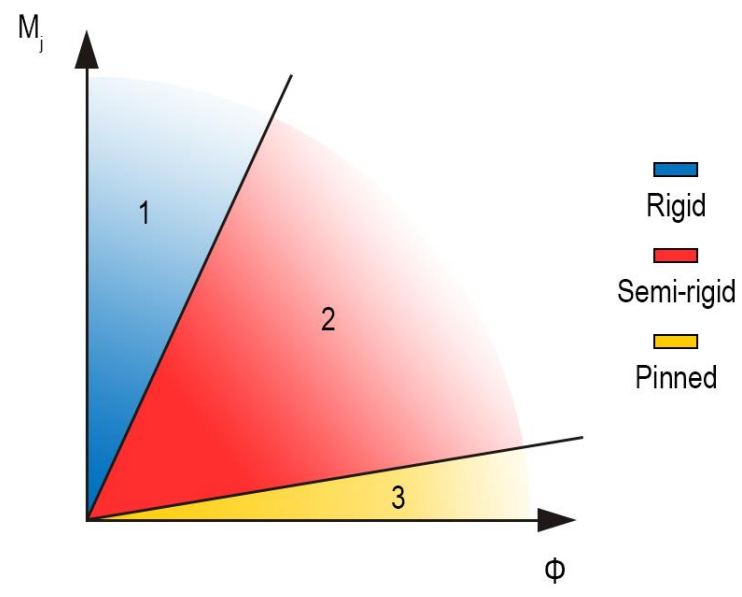

Figure 3 Classification of joints by stiffness

Figure 3 shows the zones of different classes of joint stiffness. The zones were delineated by boundary lines, where the slope represents the initial rotational stiffness of the joint $\left(S_{\text {j.,ini }}\right)$. Every joint with $S_{\text {j,ini }} \geqslant k_{b} E_{b} / L_{b}$ is considered nominally rigid (Zone 1). All joints with $S_{j, \text { ini }} \leqslant 0,5 \mathrm{El}_{\mathrm{b}} / \mathrm{L}_{\mathrm{b}}$ belong to Zone 3 and are classified as nominally pinned. Factor $k_{b}$ depends on the classification of the steel frame ( 8 for braced, and 25 for non-braced frames), and $E, I_{b}$, and $L_{b}$ represent the properties of the beam, modulus of elasticity, second moment of area, and span of the beam (center-to-center of columns), respectively. All joints that are not in Zone 1 or 3 are classified as semi-rigid (Zone 2).

Depending on the relationship between the bending moment in a joint $\left(\mathrm{M}_{\mathrm{j}, \mathrm{Ed}}\right)$ and the joint moment resistance $\left(\mathrm{M}_{\mathrm{j}, \mathrm{Rd}}\right)$, the value of the spring rotational stiffness may differ. For bending moments lower than $2 / 3 \mathrm{M}_{\mathrm{j}, R \mathrm{R}}$, the $S_{\mathrm{j}, \mathrm{ini}}$ should be incorporated in the analysis model, whereas for bending moments higher than $2 / 3 \mathrm{M}_{\mathrm{j}, R d}$ the $S_{\mathrm{j}, \mathrm{ini}}$ should be divided by $\eta$, as shown in Figure 4. The value of $\eta$ depends on the joint type and is defined in EN 1993-1-8 (Table 5.2) [1].

After joint stiffness classification, a structural designer must assign an appropriate rotational stiffness to the model. Figure 4 shows the effect of the relationship between the bending moment in the joint, $\mathrm{M}_{\mathrm{j}, \mathrm{Ed}}$, and the joint moment resistance, $\mathrm{M}_{\mathrm{j}, \mathrm{Rd}}$, on the joint rotational stiffness that should be incorporated in the model. Hence, by performing a structural analysis of the entire structure, more realistic bending moments and accompanying forces are obtained. Bending resistance is another important property of joints. It represents the value of the bending moment that can be applied to a particular joint or can be safely transmitted from one structural member (beam-tocolumn). 

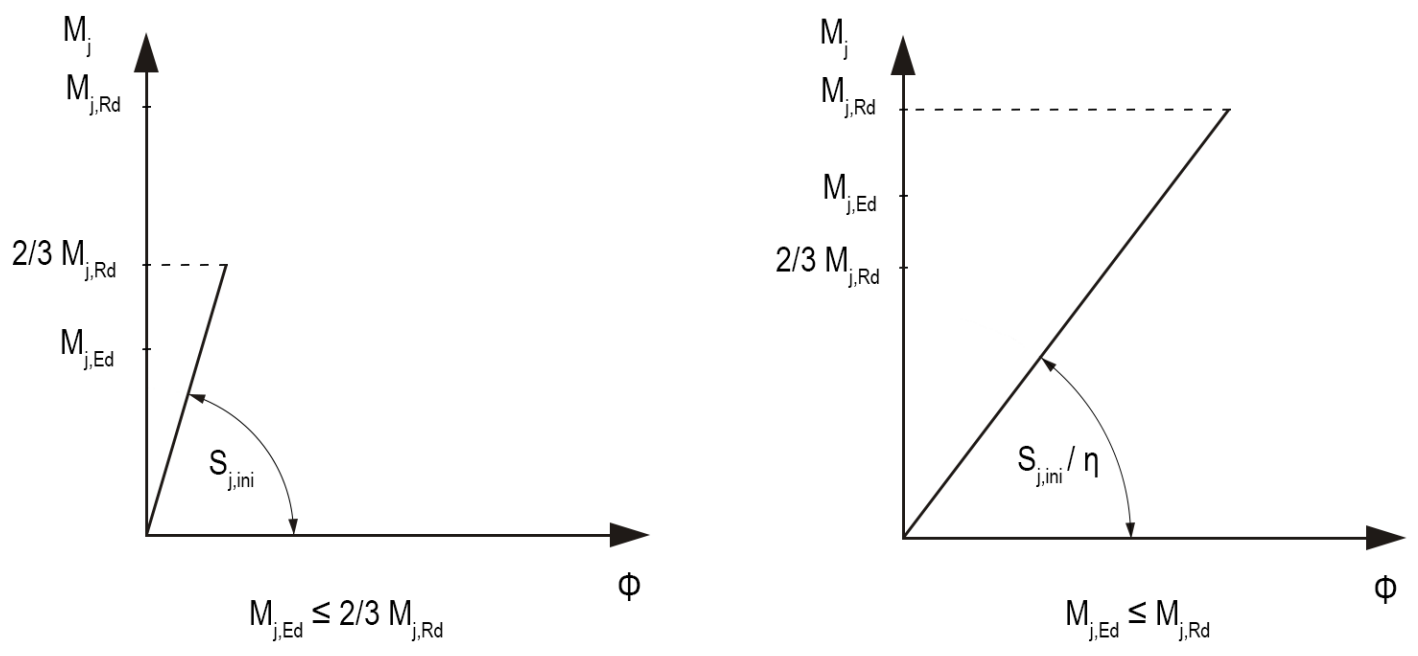

Figure 4 Rotational stiffness as a function of bending moment

After performing a structural analysis and design of structural members, an appropriate joint that satisfies all requirements should be designed. This procedure is typically the most demanding and time consuming. Moreover, it is questionable whether satisfactory optimal results were obtained via the abovementioned effort. Selecting the appropriate joint relies not only on the main structural properties, but also other factors, such as feasibility, economic profitability (including the material cost and the work cost to execute the joint), and performance [9].

\section{APPLICATION OF GDM FOR OPTIMAL DESING OF STEEL FRAMES/JOINTS}

\subsection{General}

The overall work of structural steel designers can be categorized into multiple steps, i.e., from the conceptual design to the selection of the optimal configuration of the members. All these steps are associated with each other; as such, every change in either of them will alter the others. Hence, a structural designer must possess good insight into all the steps, and the final result should be obtained in a short duration. Moreover, a structural designer must manage all types of issues such as the material behavior of all components, member behavior, stiffness and stability of the structure, and durability to achieve the desired goals. These issues collectively create a complex problem that must be solved promptly and accurately by a structural designer. Relying on previous experience may not be optimal, whereas advanced methods, such as the GDM, are extremely useful for achieving an optimal solution.

From the computing perspective, the GDM provides a significant number of configurations based on the specified parameters, which can be classified into two types: constant parameters (defined by the user) and variable parameters. Constant parameters are those defined by the user after performing the analysis and design of the structural system. These parameters include the joint type/configuration, member cross-section, material, type of global structural analysis, frame type, and beam length. They are fixed and will not be changed when using the GDM. In the analyzed sway steel frame with 7,5 m beam lengths, the cross-sections of the beams and columns were IPE 360 and HEB 240, respectively. All frame members were made of S355 steel and connected with bolted beam-to-column joints. Subsequently, a global first-order elastic analysis was performed. The abovementioned parameters are the constant parameters, or the input parameters, used in our study.

Variable parameters are defined inside the programming code and can be changed when using the GDM to obtain various configurations. These parameters are changed based on the set of rules defined when using the GDM, and they can be combined using constant parameters to obtain a significant number of possible configurations. In the analyzed example, one configuration represents a joint configuration that is composed of different components such as bolts, plates, haunches, stiffeners, and welds (Table 1). These components can be varied depending on the thickness, dimensions, and material. For example, bolts can be varied by the steel grade, diameter, and location in the joint to enable different bolt arrangements. Bolts are a specific case because of the 
execution and design rules defined in EN 1993-1-8 [1]. They must be set at an appropriate clear distance between them or the distance from the other plate or edge of the plate. All these rules are set in an algorithm that is used for every possible configuration.

Table 1 Variable parameters used in GDM for analysis of beam-to-column joint configurations

\begin{tabular}{cccccccc}
\hline Parameters & Haunch & $\begin{array}{c}\text { Web } \\
\text { Plate } \\
\text { (column) }\end{array}$ & $\begin{array}{c}\text { Horizontal } \\
\text { Stiffener } \\
\text { (column) }\end{array}$ & $\begin{array}{c}\text { Vertical } \\
\text { Stiffener } \\
\text { (beam) }\end{array}$ & $\begin{array}{c}\text { Plate thickness } \\
{[\mathrm{mm}]}\end{array}$ & $\begin{array}{c}\text { Number of } \\
\text { Bolt Rows }\end{array}$ & Bolt Size \\
\hline & Yes/No & Yes/No & Yes/No & Yes/No & $20,25,30,35,40$ & $2-12$ & $\begin{array}{c}\text { M16, M18, M20, } \\
\text { M22, M24 }\end{array}$ \\
\hline
\end{tabular}

The next section describes the overall design steps of the GDM based on an example of the steel frame design.

\subsection{Description of structural system}

The first step in the design process is the conceptual design of the building, which is proposed based on the architectural project of the client and the construction conditions. The main load-bearing steel structural system is defined based on the overall dimensions of the building. Subsequently, structural materials and presumed member sections with all the components used in the structure are defined. The abovementioned processes constitute the preliminary selection phase, and they are subjected to changes through iterations in the design.

As an example, a two-bay two-story steel frame was analyzed, and because a type of floor where the main girder (beam) is laterally braced was used, the beam stability was ensured. This implies that only the cross-section was considered for the beam. The frame geometry with the cross-section of the members is shown in Figure 5. Analysis and design were performed on a three-dimensional model with load cases of self-weight, imposed load (1,0 and $2,2 \mathrm{kN} / \mathrm{m}^{2}$ on the first floor and roof, respectively), live load $\left(1,0\right.$ and $0,5 \mathrm{kN} / \mathrm{m}^{2}$ on the first floor and roof, respectively), wind load (over pressure coefficients and basic wind velocity of $20 \mathrm{~m} / \mathrm{s}$ ), and snow load $0,5 \mathrm{kN} / \mathrm{m}^{2}$ ). The governing combination for the design of the analyzed beam-to-column joint was as follows: 1,35 (self-weight + installations) $+1,5$ snow $+0,9$ wind $+1,05$ live load.

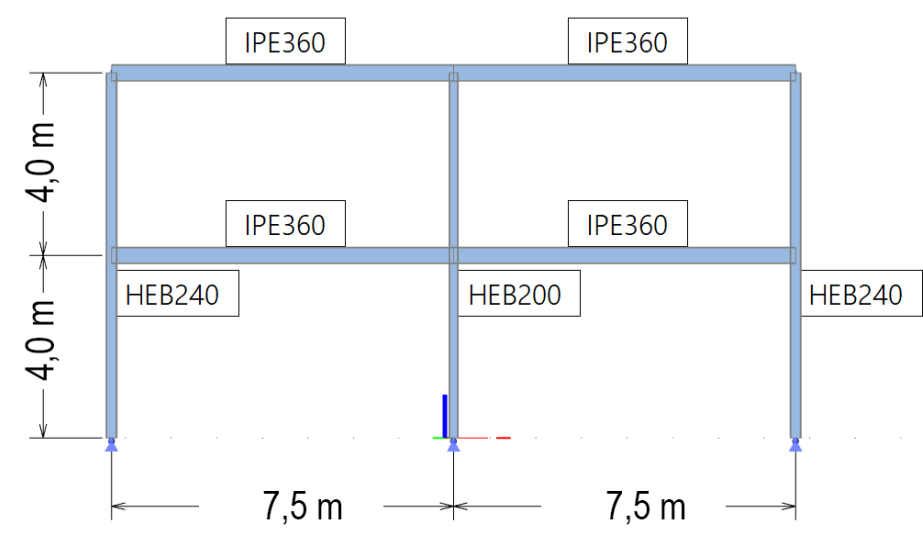

Figure 5 Geometry and cross-section of members for main frame

\subsection{Bending moment distributions}

It is beneficial to categorize optimization into different levels such that a structural designer can decide the extent of optimization. First-level optimization involves the use of nominally rigid joints. In this case, all optimization is 
associated with the optimal utilization of members and the optimization of the rigid joint configuration, which implies obtaining a joint rotational stiffness near the rigid boundary. Even though better utilization of members can be achieved using rigid joints, the use of rigid joints near the rigid boundary is advisable because of the joints reduced material and total fabrication time afforded.

As mentioned earlier, the first step in obtaining a more optimized structure is to utilize its members more effectively by assuming a rigid connection between members (rigid joints). In the analyzed case, this depends primarily on the distribution of the bending moment. After every design iteration, new bending moments and the accompanying force distributions are obtained, and a structural designer will change the member sections accordingly until the optimal member utilization is not satisfied. When using a nominally pinned beam-to-column joint, the bending moments in the middle of the beam will increase, whereas the moment at the end of the beam will increase when using a nominally rigid beam-to-column joint. Hence, for the global optimization of steel structures, real semi-rigidity of joints should be considered. The bending moment distribution for the analyzed frame with nominally rigid joints and the optimal utilization of members are shown in Figure 6.

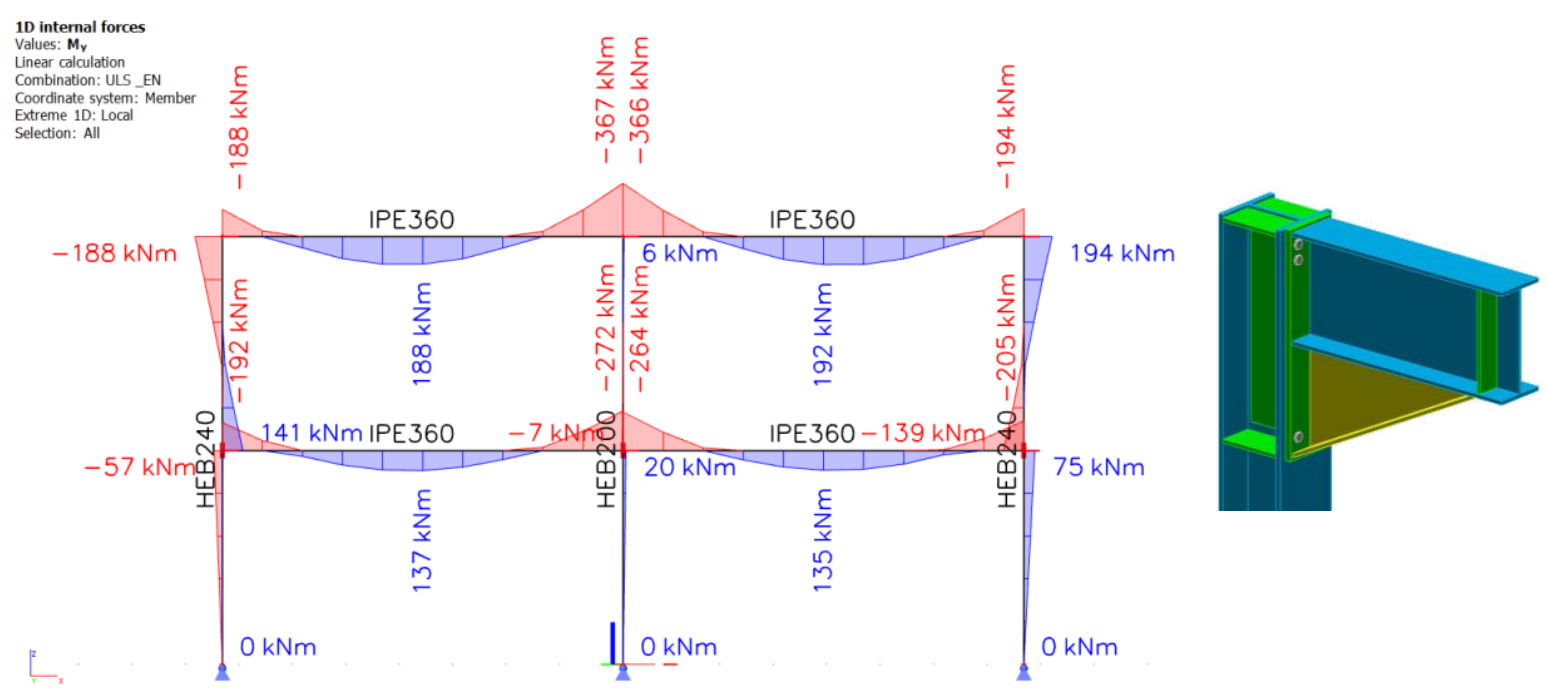

Figure 6 Moment diagram for frame with rigid joints $(S j=13800 \mathrm{kNm} / \mathrm{mrad})$

Although second-level optimization is more accurate, it is more time consuming. This implies that the structure can be analyzed using less rigid joints, i.e., semi-rigid joints. If a structural designer decides to use less rigid joints and shift from a rigid to a semi-rigid zone, as shown in Figure 3, the bending moment distribution and hence the member sections will change. If this case, further structural analysis (and design) is necessitated. Finally, an adequate change in all the joint rotational stiffnesses in the model will result in a more optimized structure with a more realistic bending moment distribution (Figure 7).

Kralj, A, Skejić, D 


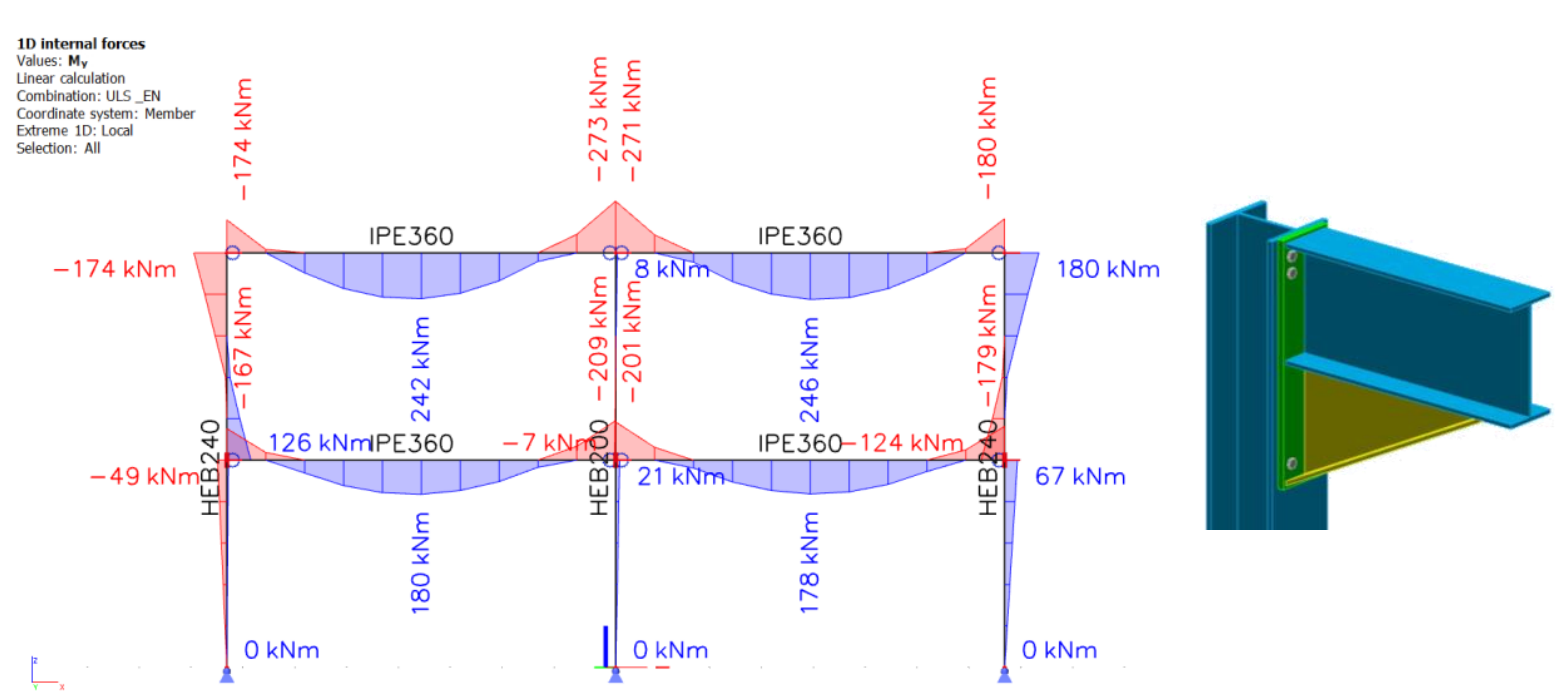

Figure 7 Moment diagram for frame with semi-rigid joints $\left(S_{j}=3650 \mathrm{kNm} / \mathrm{mrad}\right)$

In the analyzed frame, the beam was utilized effectively; however, the section was not reduced because of the serviceability limit state requirements. In addition to member optimization, using fewer stiffeners in a joint configuration will be beneficial, which will ultimately decrease the cost and overall work. The procedure for gradually reducing the stiffness is explained in Section 4.4 .

\subsection{Target joint properties}

In Section 4.3, two levels of optimization (first and second levels) are presented. In this section, these two levels are presented based on the joint properties to be determined. Once the first-level optimization is performed, the optimal rigid joint configuration is defined. Hence, the boundary line between the rigid and semi-rigid zones must be defined, as shown in Figure 8 (see Section 3).

Second-level optimization is achieved by defining the optimal rigid joint from the first-level optimization. With the main goal of reducing the total fabrication costs, including work such as cutting and welding, a structural designer removes the joint components (primarily stiffeners) and designs less rigid joints that will likely belong to the semi-rigid zone. Unlike first-level optimization, this level requires iterative structural analysis and optimal member design.

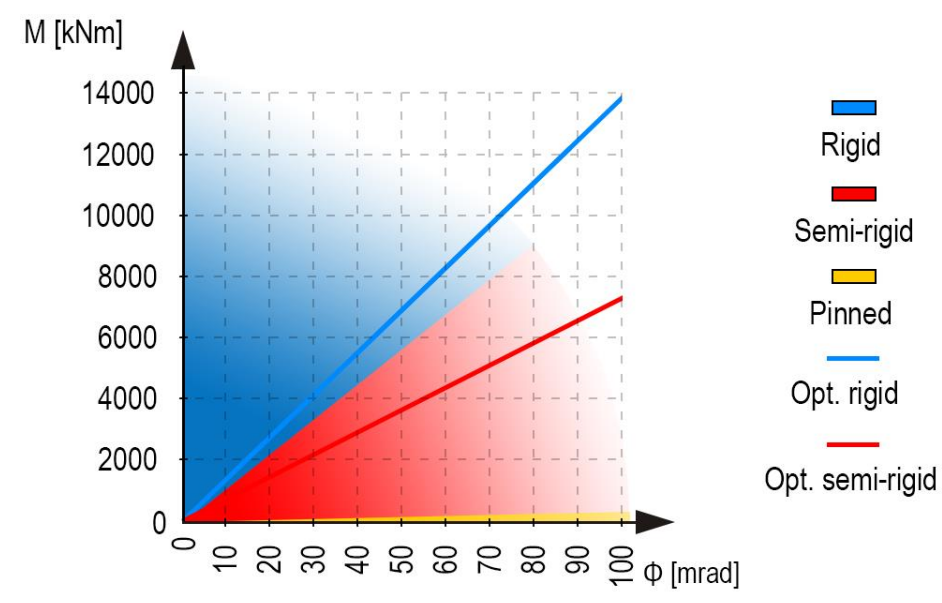

Figure 8 Classification boundary lines and optimal solutions

Kralj, A, Skejić, D 


\subsection{Possible joint configurations}

After performing the analysis and design of the structure within the first-level optimization, provided that the joints are rigid, no further change will occur in the model. Hence, after the rigid boundary of joint classification (Chapter 3 ) is defined, the best match can be determined. In the GDM, many configurations are obtained automatically, and then they are categorized based on the rotational stiffness. The analysis of many configurations ensures that the configuration is the nearest to the rigid boundary.

The starting point for the second-level optimization is the configuration from the first-level optimization. The key is to identify a less rigid joint configuration that will reduce the overall fabrication cost. Using a less rigid configuration, a structural designer must realize that changes may occur in the structural system. In this case, the GDM can be used to identify a configuration that will be optimal from the perspective of overall costs. It provides all possible configurations that are well categorized by parameters as well as accompanying images. Hence, a structural designer can easily and promptly decide if it is better, for example, to remove the beam web stiffener, column web stiffener, or haunch, or change other components. The process to identify the optimal joint configuration will be explained further based on the analyzed frame structure.

\subsection{Identification of optimal joint configuration}

Generally, after performing the final analysis and design, the structural designer will set the input parameters (Figure 2) of the GDM that are obtained directly from the structural system. Subsequently, the configurations are obtained and organized based on the rotational stiffness, as shown in Figure 9. Typically, several configurations around the boundary stiffness are obtained; thereafter, the most suitable configuration from the perspective of execution will be selected.

The first seven vertical axes of the graph in Figure 9 represent the variable parameters defined in Table 1. The last two axes represent the joint bending resistance (BR) and joint rotational stiffness (RS) for each analyzed joint configuration. In the analyzed frame, after the final analysis and design, the configurations around the rigid boundary line $(11400 \mathrm{kNm} / \mathrm{mrad})$ are considered. The configurations nearest to the boundary have a bending resistance that is significantly higher than the bending moment obtained from the analysis of the structure $\left(\mathrm{M}_{\mathrm{j}, R d}=\right.$ $388 \mathrm{kNm} \gg M_{\mathrm{j}, \mathrm{Ed}}=194 \mathrm{kNm}$ ). Finally, a configuration that is optimal from the perspective of bending resistance and rotational stiffness is selected $\left(\mathrm{M}_{\mathrm{j}, R d}=282 \mathrm{kNm}>\mathrm{M}_{\mathrm{j}, \mathrm{Ed}}=194 \mathrm{kNm}\right.$, Figure 9 - highlighted blue line $)$.

Second-level optimization depends on the configuration selected from the first level. The procedure for gradually decreasing the rotational stiffness is described in Section 4.5. The structural designer typically begins from the first-level optimization afforded by the GDM and then continues to identify the most appropriate configuration. If the reduced joint rotational stiffness affects the behavior of a structural system (change section of members), then a GDM with different input parameters must be executed.

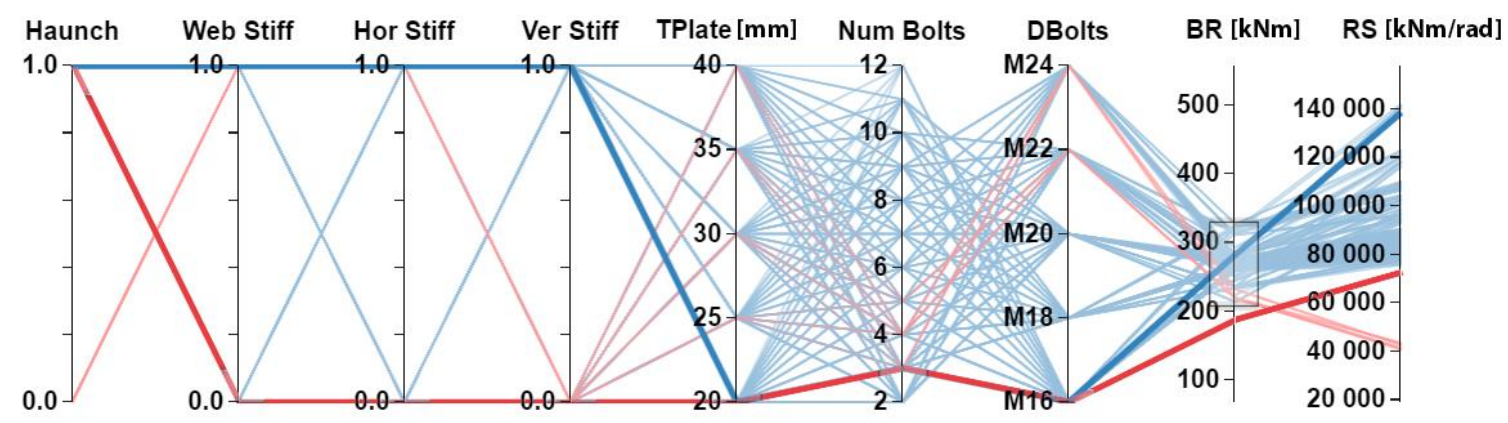

Kralj, A, Skejić, D 


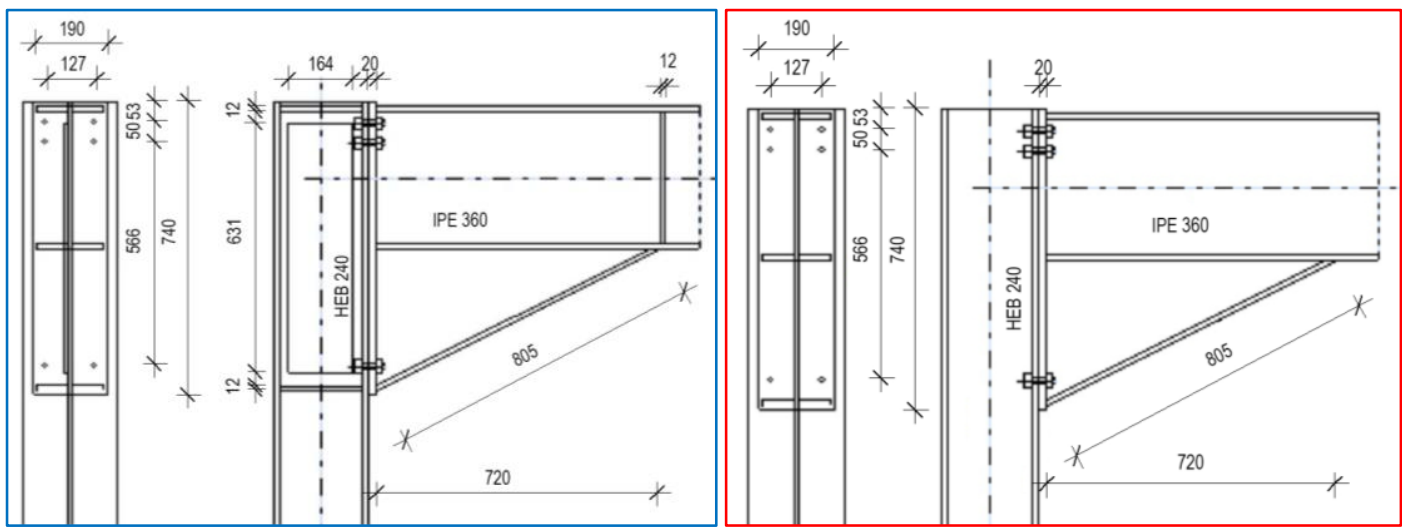

Figure 9 Filtering configurations for optimization

For the second-level optimization, the analysis of joint configurations based on the components is crucial. The GDM is represented uniquely via the PCP (Section 1) and affords an extremely efficient organization of configurations based on the components (parameters). The rotational stiffness is reduced using the appropriate configurations and eliminating all joint components that reduce the overall work, for example, cutting and welding. However, reducing the joint rotational stiffness can adversely affect the structural system, for example, increase the member sections and, consequently, the overall weight of the structure. The red line in Figure 9 shows the optimal configuration obtained from reducing the number of components from the first-level optimization.

After performing the first-level optimization, the number of components reduced. In the analyzed example, a structural designer decided to eliminate a supplementary column web plate, two column stiffeners, and one beam stiffener. Figure 9 shows a direct comparison of the first- and second-level joint configurations based on workshop drawings. Table 2 presents a comparison of the variable (input) and output parameters for a better depiction of the differences.

Table 2 shows that by reducing the number of components such as the web plate, beam stiffener, and column stiffener, the members can be utilized more effectively, and most importantly, the work on the joint (cutting and welding) can be reduced significantly. In the example presented herein, the sections were not reduced owing to the SLS requirement for the main beam, which indicated a vertical displacement of $28 \mathrm{~mm}(\mathrm{~L} / 250=7500 / 250=30$ $\mathrm{mm})$.

Table 2 Comparison between two configurations (first and second levels)

\begin{tabular}{|c|c|c|c|c|c|c|c|c|c|c|}
\hline \multirow[b]{2}{*}{ Configuration } & \multicolumn{7}{|c|}{ Variable Parameters } & \multicolumn{2}{|c|}{ Output Parameters } & \multirow[b]{2}{*}{$\begin{array}{c}\text { Joint } \\
\text { Classification }\end{array}$} \\
\hline & Haunch & $\begin{array}{l}\text { Web } \\
\text { Stiff }\end{array}$ & $\begin{array}{l}\text { Hor } \\
\text { Stiff }\end{array}$ & $\begin{array}{l}\text { Ver } \\
\text { Stiff }\end{array}$ & $\begin{array}{l}\text { TPlate } \\
{[\mathrm{mm}]}\end{array}$ & $\begin{array}{l}\text { Num } \\
\text { Bolts }\end{array}$ & DBolts & $\begin{array}{c}\begin{array}{c}\text { Bending } \\
\text { Resistance }\end{array} \\
{[\mathrm{kNm}]}\end{array}$ & $\begin{array}{c}\text { Rotational } \\
\text { Stiffness } \\
{[\mathrm{kNm} / \mathrm{rad}]}\end{array}$ & \\
\hline $\begin{array}{l}\text { First Level } \\
\text { Optimization }\end{array}$ & Yes & Yes & Yes & Yes & 20 & 3 & M16 & 282 & 138000 & Rigid \\
\hline $\begin{array}{l}\text { Second Level } \\
\text { Optimization }\end{array}$ & Yes & No & No & No & 20 & 3 & M16 & 188 & 73000 & Semi-rigid \\
\hline
\end{tabular}

Additionally, the cost of the structural members did not change because the sections of the members remained unchanged. By contrast, the cost of the joint configuration reduced significantly. For the first-level optimization configuration, $54,1 \mathrm{~kg}$ of steel for the stiffeners and $11,93 \mathrm{~m}$ long fillet welds $(\mathrm{a}=5 \mathrm{~mm})$ was used. In comparison, $29,4 \mathrm{~kg}$ of steel for the stiffeners and $5,82 \mathrm{~m}$ long fillet welds $(5 \mathrm{~mm}$ ) were used for the second-level optimization. Consequently, approximately $55 \%$ of the steel stiffeners' weight and approximately $51 \%$ of the weld

Kralj, A, Skejić, D 
length were reduced. A significant reduction in the weld length results in a considerable reduction in the total fabrication costs.

\section{CONCLUSION}

The implementation of the GDM based on the example presented herein contributed positively to the structural design process and design efficiency improvement. In addition to a more realistic final design, it significantly reduced the design time and provided structural designers with better insights into the effects of joint components on the joint main structural properties, such as the bending resistance and rotational stiffness. Results obtained from the GDM provided interactive insights into numerous analyzed joint configurations, thereby facilitating structural designers in designing optimum joints from reliability and economic aspects. Such an approach enables better decision-making, which often leads to overall work and material reduction.

The presented design process was organized logically, in which a structural designer began from a classified rigid configuration to optimize the joint while remaining in the rigid zone. Subsequently, by gradually reducing the most expensive joint components, the joint became semi-rigid. During this process, a global analysis should be performed, and changes in the accompanying member sections should be prioritized.

A more realistic simulation of joint behavior can be achieved using the component-based finite element method (CBFEM), which is successfully implemented in the software IDEA StatiCa [12]. The generative design combined with the CBFEM will yield more realistic and more promising results; however, new issues will emerge, which necessitate further investigations.

\section{References}

[1] European Committee for Standardization (CEN) 2014: Eurocode 3: Design of Steel Structures - Part 1-8: Design of Joints (EN 1993-1-8:2005+AC:2009)

[2] Tariq, M. 2019: Generative design, Presentation, CECOS University Peshawar, Pakistan, https://www.researchgate.net/publication/334559542_Generative_design, Accessed 10 December 2021

[3] Ntintakis, I.; Stavroulakis, G. E. 2020: Progress and recent trends in generative design, 7th International Conference of Materials and Manufacturing Engineering (ICMMEN 2020), MATEC Web of Conferences, 318, 01006. https://doi.org/10.1051/matecconf/202031801006

[4] Sun, H.; Ma, L. (2020). Generative Design by Using Exploration Approaches of Reinforcement Learning in Density-Based Structural Topology Optimization, Designs, (2), 10. https://doi.org/10.3390/designs4020010

[5] Johan, R. et al. 2019: Building intelligence through generative design, Intelligent \& Informed, Proceedings of the 24th International Conference of the Association for Computer-Aided Architectural Design Research in Asia (CAADRIA), Haeusler, M.; Schnabel, M. A.; Fukuda, T. (Eds.), 1, pp. 371-380.

[6] Fischer, T.; Herr, C. M. 2001: Teaching Generative Design, The Proceedings of the Fourth International Conference on Generative Art 2001, Soddu, C. (Ed.), Generative Design Lab, DiAP, Politechnico di Milano University.

[7] Moustafa, R. E. 2011: Parallel coordinate and parallel coordinate density plots, Wiley Interdisciplinary Reviews Computational Statistics, 3 (2), pp. 134-148. https://doi.org/10.1002/wics.145

[8] Skejić D.; Džeba I. 2015: Celične konstrukcije, Sveučilište u Zagrebu, Građevinski fakultet, Sveučilišni priručnik, Zagreb, Croatia.

[9] Skejić, D.; Jamaković, S. 2012: Projektiranje ekonomičnih čeličnih okvirnih konstrukcija, Electronic Journal of the Faculty of Civil Engineering Osijek-e-GFOS, 3 (4), pp. 1-13.

[10] Dujmović, D.; Androić, B.; Skejić, D. 2003: Modeliranje priključaka čeličnih okvirnih konstrukcija, Građevinar 55 (6), pp. 339-348.

[11] Dujmović, D.; Skejić, D.; Androić, B. 2003: Modeliranje priključka nosač-stup prema Eurokodu 3, Građevinar 55 (7), pp. 397-405.

[12] SCIA 2020: Tutorial - IDEA StatiCa connection, https://www.scia.net/, Accessed 10 December 2021

Please cite this article as: Kralj, A., Skejic, D.: Generative design of structural steel joints, Electronic Journal of the Faculty of Civil Engineering Osijek-e-GFOS, 2021, 23, pp. 22-32, https://doi.org/10.13167/2021.23.3

Kralj, A, Skejić, D 